\title{
Source parameter estimation of Indian Ocean earthquake from observation of GRACE Gravity Gradient Tensor
}

\author{
Armin Rahimi ${ }^{1, *}$, Mehdi Raoofian Naeeni ${ }^{2}$ \\ ${ }^{1}$ Faculty of Surveying and Geomatics Engineering, University of Tehran, Tehran, Iran \\ ${ }^{2}$ Faculty of Geodesy and Geomatics Engineering, K. N Toosi University of Technology, Tehran, Iran
}

\begin{abstract}
Article history
Received February 16, 2017; accepted August 31, 2017.

Subject classification:

Undersea earthquakes, Gravitational gradient change, Fault parameters, GRACE observations, Genetic algorithm, Dislocation theory
\end{abstract}

\begin{abstract}
In this study, the focal mechanism of Indian Ocean earthquake is determined by combination of GRACE gravity gradient change and analytical model of Okubo [1992). To do so, the co-seismic gravity gradient change resulting from Indian Ocean earthquake is derived using monthly solution of GRACE level 02 data after removing the contaminations from hydrological effects and post-seismic creep. Since, De-striping methods lead to reduction and distortion of a co-seismic gravity change signal, it is suggested to compute a set of gravity gradient tensor components e.g. $\Delta V x x$ and $\Delta V x z$, because they are more sensitive to small-scale signals and they reduce the striping errors without need to any de-striping filtering. Then the computed gravity gradient components are compared with the gravity gradient components from Okubo model [1992], which accounts the focal mechanism of the earthquake. By the way, the nonlinear inversion algorithm is constructed and solved by Genetic algorithm to find the best values of fault parameters for Indian Ocean earthquake. For better constraining the fault parameters in the inversion process, a sensitivity analysis is also conducted which reveals that the selected model is highly sensitive to a strike angle, dip angle, length, width and average slip, although it is less sensitive to a depth of a fault. The ultimate optimal estimate of the fault parameters shows a good correspondence compared with some existing slip models obtained by various constraints or via inversion of seismic observations.
\end{abstract}

\section{Introduction}

Earthquake affects lives of many people every year and poses inevitable threats to everyone who lives in seismically active regions. Improved quantification of earthquake events, such as geometries and orientations of the faults, is very important to understand the mechanism of earthquake and subsequently leads to better prediction of such events.

Traditionally, different data sources including seismological data, GPS data, Interferometric Synthetic Aperture Radar data (InSAR) and tsunami data have been used to determine the physical and geometric parameters, quantifying the earthquake faulting characteristics. However, there are some limitations on those traditional methods for estimating the source parameters of large undersea earthquakes [Stein et al. 2012].

Earthquake causes mass redistribution in the Earth's crust and upper mantle, and permanently changes the Earth's gravity field. Therefore, it is possible to use the detected gravity change, as an independent and valuable observation to study earthquake mechanism. GRACE offers a new means to observe mass change due to earthquake deformations. It provides uniform coverage over both oceans and lands and thus it is a very useful complementary sensor in a conjunction with other earthquake measurements particularly for monitoring undersea earthquake.

Earthquake results from a sudden rupture on the surface of the fault. Many scientists developed mathematical theories to relate the earthquake deformations, such as displacement, strain, tilt and gravity change, with the geometry of the fault system. By the way, the dislocation theory has been generally accepted as a powerful tool to interpret the deformation and gravity change due to Earthquakes. Nowadays, there are Different models of dislocation for the study of Earthquake source parameters. Some of them are valid for a homogeneous half-space such as those of Okada [1985] and Okubo [1991, 1992], and some others for 
homogeneous or a heterogeneous sphere like those of sun and Okubo [1993, 1998]. They are usually used to interpret observed co-seismic deformations and gravity change. Due to mathematical simplicity and ease of computer programing, Okubo's [1991, 1992] models for evaluating potential and gravity changes have been widely used as standard formulations [Sun et al. 2009]. Okubo [1991] computed gravitational potential change in a homogenous elastic half space due to a point dislocation. He developed his theory to a rectangular fault in a half space and computed gravitational potential and gravity change in the form of fault parameters [Okubo 1992].

There are several attempts to constrain fault geometry with GRACE observations. Cambiotti et al. [2011] used GRACE observations to constrain fault depth for 2004 Sumatra-Andaman earthquake. Wang et al. [2012a] used Markov Chain Monte Carlo algorithm to simultaneously estimate fault-plane length, width and slip on the fault using co-seismic gravity change observable from GRACE for 2010 Chilean Maule earthquake. Similar techniques have been applied for 2011 Tohoku earthquake [Wang et al. 2012b]. Some Field quantities could better extract seismic signals in a comparison with the gravity change observed by GRACE satellites. Among these field quantities, some gravity gradient components (i.e. $\Delta \mathrm{Vxx}$ and $\Delta \mathrm{Vxz}$ ) can better outline the rupture lines and are more sensitive to small-scale signals [e.g., Li and Shen 2011; Wang et al. 2012c]. Die et al. [2014] used north components of gravity and gravity gradient changes without any de-correlation or spatial filtering to constrain seismic source parameters of the 2011 Tohoku Earthquake. Die et al. [2016] Improved source parameter estimations for five undersea earthquakes from north component of GRACE gravity and gravity gradient change measurements. Recently, the formulation of Okubo's [1991, 1992] model has been developed in order to compute the gravitational gradient changes resulting from earthquake [see Fatolazadeh et al., 2015; Wang et al., 2012c]. This analytical model was used to constrain the fault parameters of the 2010 Chile Earthquake using gravimetric observations [Fatolazadeh et al. 2017].

On 11 April 2012, the equatorial Indian Ocean region was hit in a couple of hours by the largest strikeslip earthquake ever recorded (moment magnitudes Mw8.6). Broadband seismological observations of the Mw8.6 main-shock indicated, a large centroid depth (30 $\mathrm{km}$ ) and remarkable rupture complexity [Duputel et al., 2012]. Space-borne gravimetry data from GRACE have been used to observe the co-seismic [Han et al. 2013,
Die et al. 2016] and post-seismic [Han et al. 2015] signature of the Indian Ocean earthquake. Han et al. [2013] demonstrated the fault parameters inversion of large earthquakes, including that of Indian Ocean, based on multiple centroid moment tensors and normal mode formulation. They inverted four double-couple parameters (i.e. strike, dip, rake and scalar seismic moment) simultaneously from the gravity changes [Han et al. 2013]. Similar techniques were applied to invert the four double-couple parameters (i.e. strike, dip, rake and scalar seismic moment) for Indian Ocean earthquake from north component of GRACE gravity and gravity gradient change measurements [Die et al. 2016].

It should be mentioned that data from teleseismic networks has also been used to observe and model the co-seismic signature and slip history of the Indian Ocean earthquake [Wei 2012; Shao et al. 2012; Hayes 2012; Yue et al. 2012]. These models are shown in Figure 1. Model I, by Wei [2012], is calculated using 31 teleseismic P waveforms. Model II, by Shao et al. [2012], is calculated using 28 teleseismic broadband P waveforms, 27 broadband SH waveforms, and 45 long period surface waves. The fault that they proposed has the same direction (strike $=20$ ) as the Wei [2012] while it has distinctly different fault parameters and slip history. Hayes [2012] analyzed 38 teleseismic broadband P waveforms, 13 broadband SH waveforms, and 56 long period surface waves. He derived two slip models (Model III and IV). The first model proposed by him (model III) has approximately the same orientation as Shao et al [2012] and Wei [2012]. The second model (model IV) has completely different orientation with the first model. Regarding model V, Yue et al. [2012] used seismic wave analyses to reveal that the 11 April 2012 event had an extra ordinarily complex four-fault rupture. The main shock ruptured on a right-lateral strike slip fault trending west-northwest to east-southeast with maximum slip of 30 meter and then another rupture was triggered on a left lateral strike-slip fault that crosses the first fault. A few seconds later, two more ruptures took place around the epicenter.

In this paper, an inversion method based on genetic algorithm is conducted for estimation of fault parameters of Indian Ocean earthquake using north components of the gravity gradient tensor (i.e. $\Delta \mathrm{Vxx}$ and $\Delta \mathrm{Vxz}$ ). In completing previous researches, instead of solving for the moment tensor of a point dislocation source, we make an effort to find the focal mechanism for the finite fault model. To do so, at first, we extract the co-seismic gravity signals due to Indian Ocean earthquake from GRACE observations and 


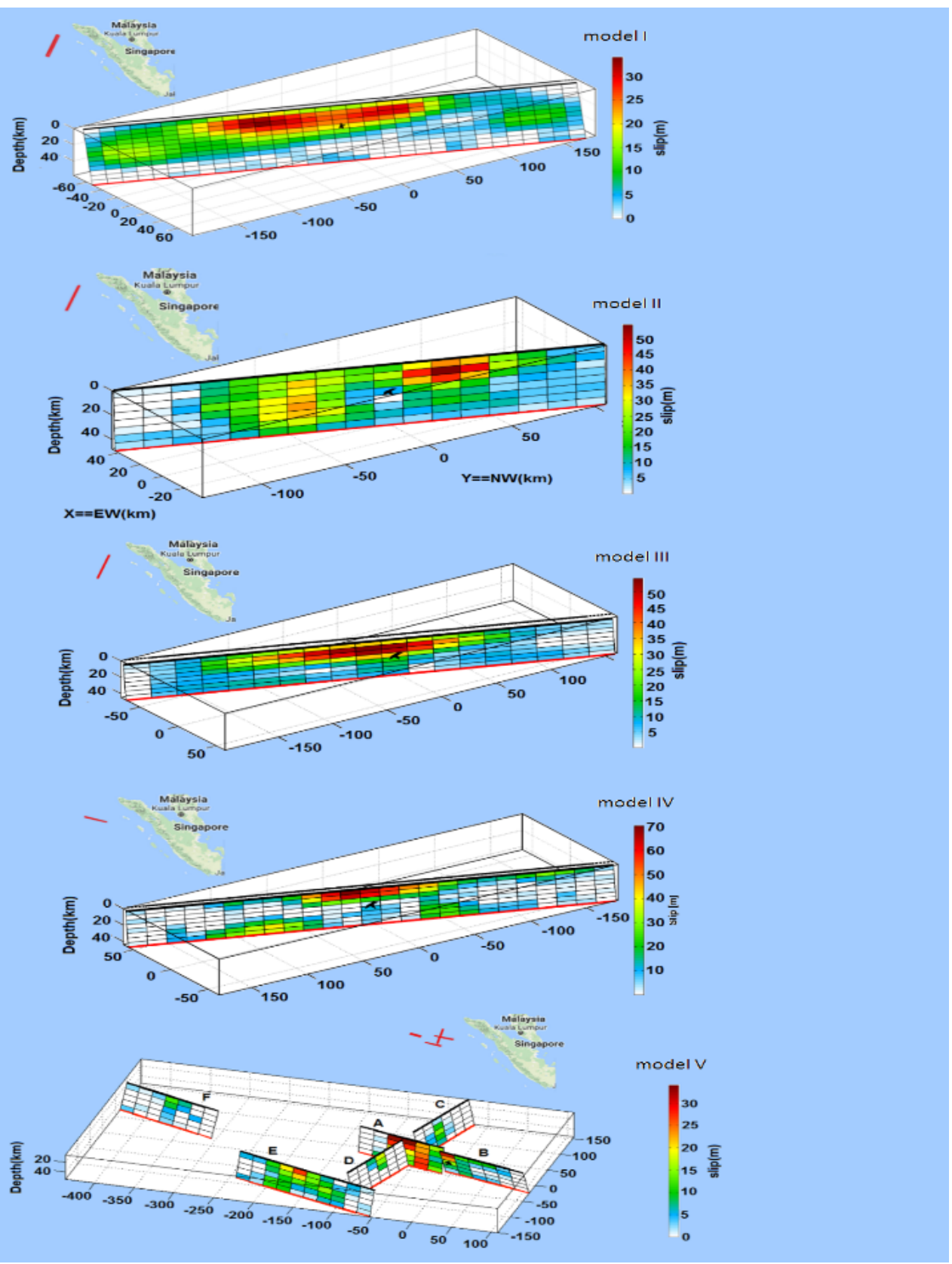

Figure 1. The slip models of Indian Ocean earthquake (http:// equake-rc.info/SRCMOD/).

then we compute the full gravity gradient change resulting from this event. Finally, we compare our observation with an Okubo model [1992] to invert for the fault parameters.

It should be emphasized that the extraction of co-seismic signal of Indian Ocean earthquake from GRACE observation needs the elimination of the effects of seasonal variations due to hydrological effects, and the influence of post-seismic creep which needs a specific considerations in the computation of co-seismic gravity gradient change.

Since the fault parameters are determined by the inversion of gravity gradient components using Okubo [1992] model, it is necessary that the sensitivity of this model to fault parameters is carefully investigat- ed to show which fault parameters can be better constrained in the inversion process. This analysis reveals that the model may be transparent with a respect to some fault parameters and thus their values should be determined from other observations.

\section{Coseismic gravity and gravity gradient change using GRACE observation}

The Gravity Recovery And Climate Experiment (GRACE) is a satellite mission jointly launched in 2002 by the National Aeronautics and Space Administration (NASA) and the Deutsche Forschungsanstalt für Luft und Raumfahrt (DLR), that makes the detailed measurements of the Earth's gravity field, as well as its temporal variations with a spatial resolution of several 

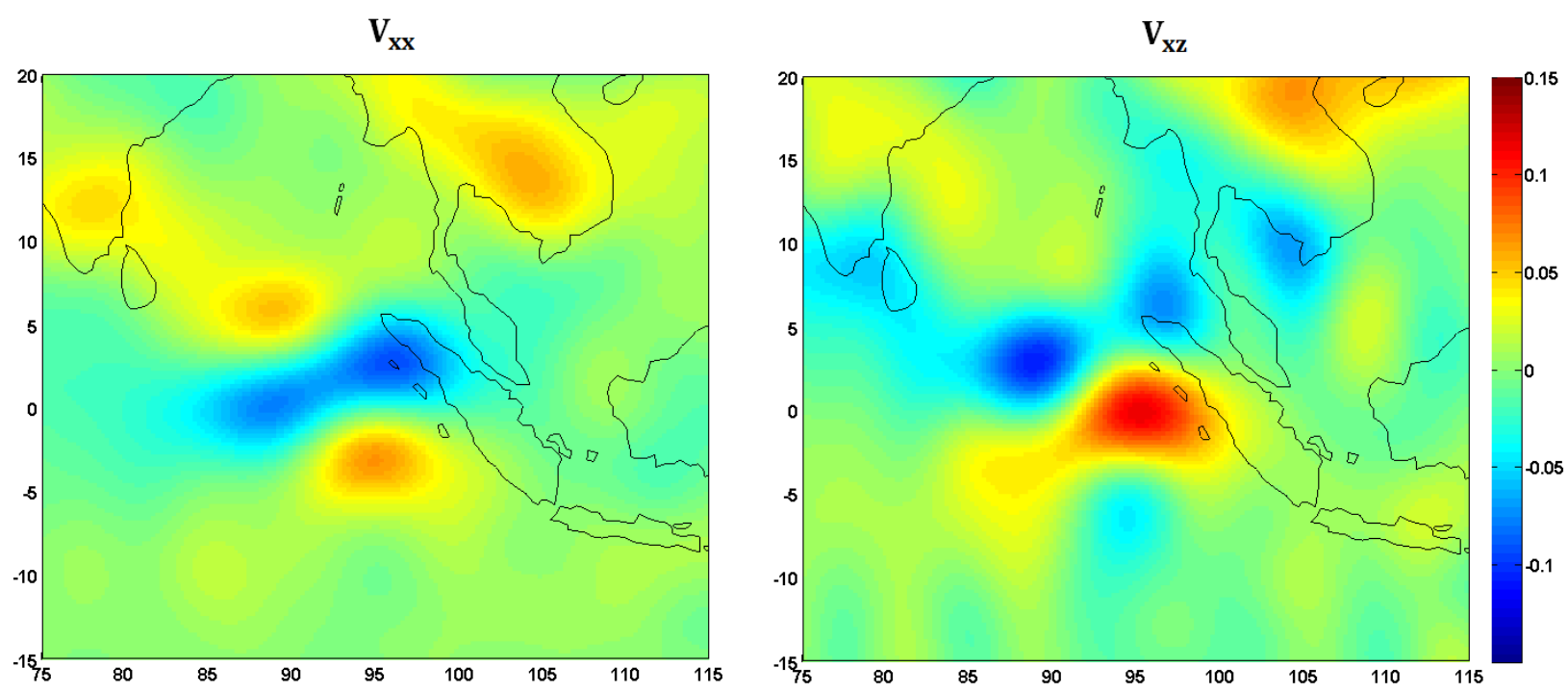

Figure 2. The post-seismic effects on two gravity gradient components $\Delta \mathrm{Vxx}$ and $\Delta \mathrm{Vxz}$.

hundred kilometers and temporal sampling of about 30 days. The responsibility for extraction of the Earth gravity field models is with the GRACE project Science Data System (SDS). The SDS is distributed between UTCSR, JPL and GFZ.

In this study, we use the Release-05 (RL05) Level-2 monthly gravitational field data products released by the University of Texas Center for Space Research (UTCSR) [see Tapley et al., 2004], which are composed of fully normalized spherical harmonic ( $\mathrm{SH}$ ) coefficients up to a degree and order 60 , corresponding to a spatial resolution of $333 \mathrm{~km}$ or longer.

Here, the monthly $\mathrm{SH}$ coefficients, $\mathrm{C}_{\mathrm{nm}}$ and $\mathrm{S}_{\mathrm{nm}}$, are used to compute the components of the gravity gradient tensor in spherical coordinates in a $1^{\circ} \times 1^{\circ}$ degree regular grid over the region of study. Since our focus is mainly on a local mass change, the local north-eastdown frame (NED) is introduced in such a way that the $\mathrm{x}$ axis is directed to the north, the $\mathrm{y}$-axis to the east, and the $z$-axis downward and then the full gravity gradient tensor in this local NED frame is obtained [Wang et al. 2012c].

Since in this study, the co-seismic gravity gradient change is considered to constrain the focal mechanism, it is necessary that the potential contamination from the post-seismic signal associated with the 2012 Indian Ocean earthquake is eliminated from GRACE observations. To do so, the gravity gradients of all months after the earthquake, from June 2012 to June 2014 (for the period of two years after the earthquake) are used to fit the following time-dependent function (Wang et al. 2012c]:

$$
y(t)=a+b\left(1-e^{-t / \tau}\right)
$$

in which $\mathrm{a}, \tau$ and $\mathrm{b}$ are the unknown parameters that must be determined from the observations of gravity gradient change to find the post seismic effects. Here, these parameters are determined by non-linear least square method. Then, the post-seismic signal which is approximated by the second term in Equation (1) is subtracted from these months' solutions [Wang et al. 2012c].

Figure 2 shows the post-seismic effects on two gravity gradient components $\Delta \mathrm{Vxx}$ and $\Delta \mathrm{Vxz}$.

It is seen that the post-seismic effects has the influence of about 0.15 miliEotvos on the gravity gradient components and should be eliminated in order to isolate co-seismic signal.

GRACE observe the gravity variations due to total mass change in the Earth system dynamics, from which, we aim to extract the related co-seismic signal. Thus, it is necessary that the other important factors in the GRACE gravity change be eliminated in order to isolate the gravity and resulting gravity gradient change due to earthquake. In this respect, the crucial effect is seasonal variations due to hydrological source. To suppress these influences and separate co-seismic signal due to Indian earthquake, we subtract two mean gravity gradient field after and before this earthquake which is known as the stacking approach based on Chen et al. [2007]. The mean gravity gradient before this earthquake is computed from 24 solutions, March 2010 to March 2012 , and the mean gravity gradient after this earthquake is computed from the last 24 solutions, June 2012 to June 2014. Data was not available for the month of May 2012 due to the observation problem of GRACE satellites. By subtract- 
ing these two mean solutions, and indeed, omitting the contaminations from post-seismic creep, the resulting gravity gradient change, contains the desired co-seismic signals, can be obtained and compared with the analytical model of Okubo [1992] to constrain the fault parameters.

\section{Analytical model of co-seismic gravity change}

The gravity change due to earthquakes can be expressed by simplified but effective way, in which earthquake is modeled as dislocations on a rectangular plane in a homogeneous elastic half-space [Okubo 1991, 1992]. Fatolazadeh et. al [2015] developed this formulation in order to compute the gravity gradient changes resulting from earthquake [see also Wang et al., 2012c].

In order to use Okubo model in a conjunction with GRACE gravity gradient change computed in the previous section, it is necessary that two auxiliary corrections are applied to Okubo model. First, one should be cautious that the analytical model of Okubo has been developed for a deformed earth surface because most traditional gravity measurements are performed on the terrain surface. However, GRACE, observe co-seismic gravity changes from space. In this case, the conventional dislocation theory cannot be applied directly to the observed data because this data does not include surface crustal deformation (the free air gravity change). Consequently, the contribution by the vertical displacement part must be removed from the Okubo model. This effect is known as the free-air correction and is expressed by the term $\beta \Delta \mathrm{h}(\mathrm{x} 1, \mathrm{x} 2)$, where $\beta$ takes into account the free-air effect due to the surface vertical motion of $\Delta \mathrm{h}$. [see Li et al., 2014, Sun et al 2010]. On the other hand, since the Indian Ocean earthquake has been occurred at the ocean floor, but the Okubo model has been developed for dry land, the second correction known as a seawater correction should also be considered. the seawater correction means, the ocean water's passive response to the co-seismic crustal displacement at the ocean floor, e.g. at the sea floor where crust goes up, water is evacuated, means there is a loss of mass; and at places where crust subsides, water flows in, means there is an increase of mass volume. These passive responses of ocean water to co-seismic crustal motion can be very large, up to the same order to the gravity change by the solid Earth deformation. In this study, we have implemented a Bouguer approximation to compute these effects on co-seismic gravity gradient change [see Fatolazadeh et al. 2017]. The necessity of seawater correction was also shown by Linage et al. [2009], Broerse et al. [2011] and Cambiotti et al [2011].
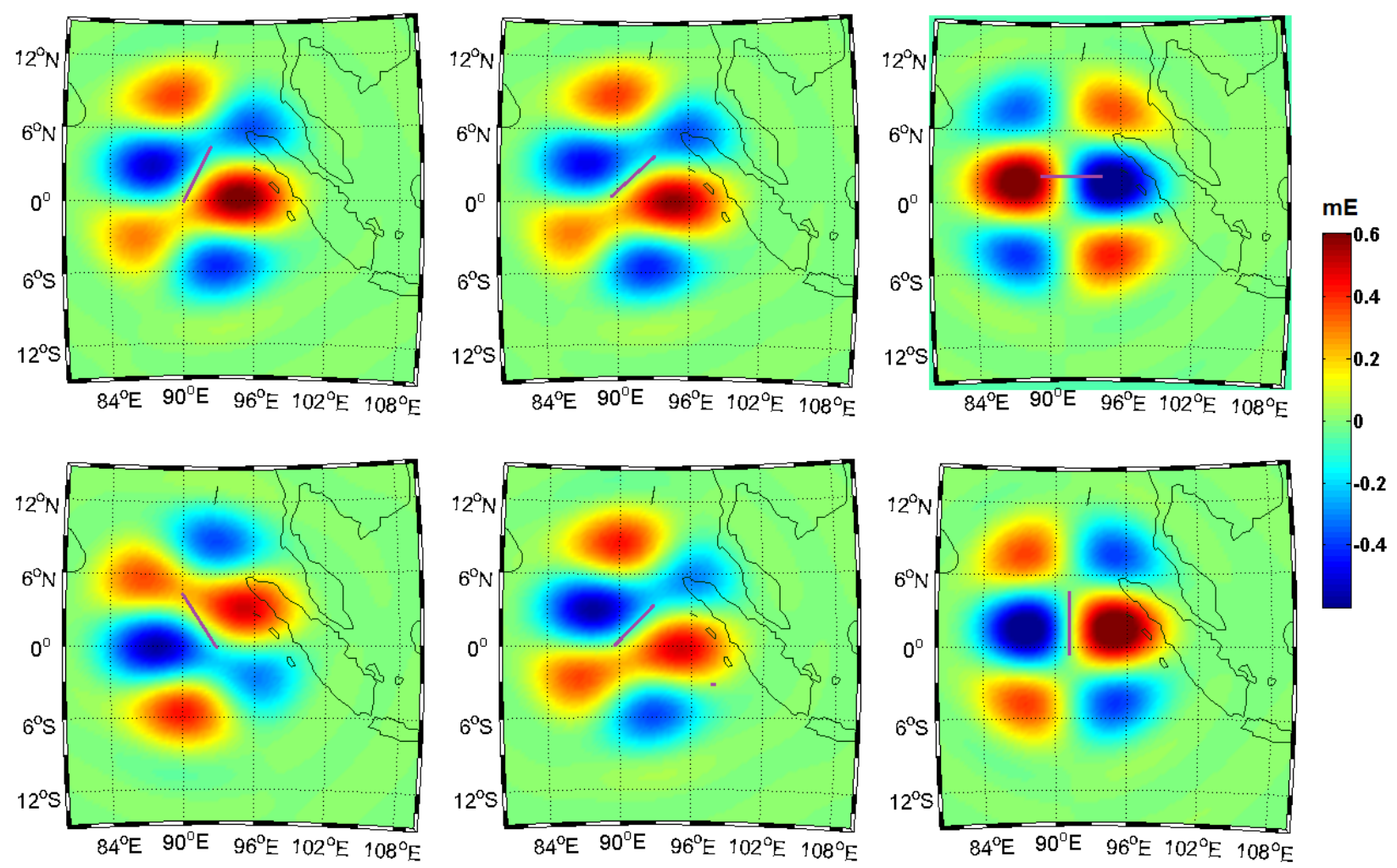

Figure 3. Sensitivity to strike angle: the pattern of $\Delta \mathrm{Vxz}$ for the fault strike angles of $20^{\circ}, 30^{\circ}, 90^{\circ}, 150^{\circ}, 210^{\circ}$ and $360^{\circ}(1-6)$. Fixed fault parameters are: fault length $380 \mathrm{~km}$, fault width $40 \mathrm{~km}$, dip angle $80^{\circ}$, depth $5.67 \mathrm{~km}$, slip magnitude $5 \mathrm{~m}$, rake angle $0^{\circ}$. The purple line shows fault orientation. (Units in miliEotvos). 


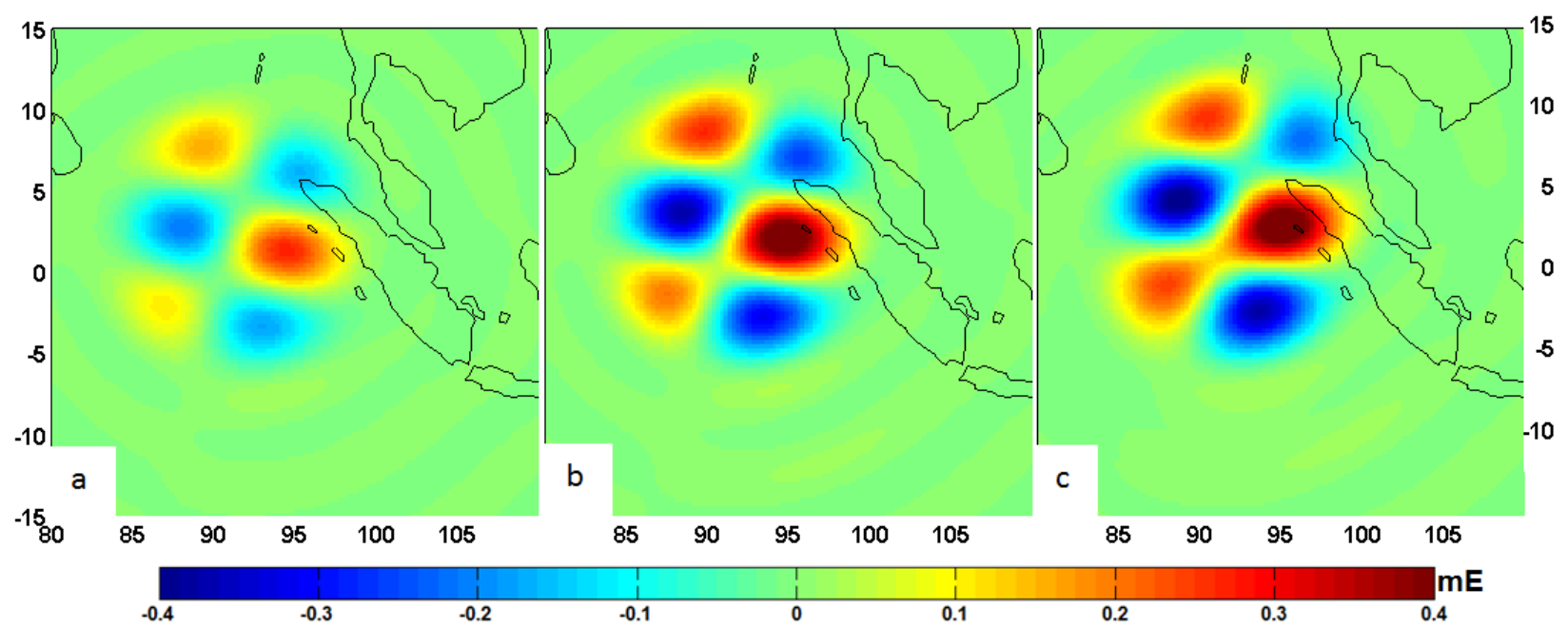

Figure 4. Sensitivity to a fault length: pattern of $\Delta V x z$ for the fault lengths (a): $200 \mathrm{~km}$, (b): $400 \mathrm{~km}$ and (c): $600 \mathrm{~km}$, fixed fault parameters are: strike angle $20^{\circ}$, fault width $40 \mathrm{~km}$, dip angle $80^{\circ}$, depth $5.67 \mathrm{~km}$, slip magnitude $5 \mathrm{~m}$, rake angle $0^{\circ}$.

\section{Sensitivity analysis of Okubo model}

It is important to note that, during the inversion process to constrain the fault parameters, some of the fault parameters may not be well constrained [see Wang et al. 2012a ,2012b]. To find out which parameters could be well constrained, a sensitivity analysis should be performed.

To demonstrate the sensitivity of analytical model to various fault parameters including fault strike angle, dip angle, depth, length, width and slip, we carry out several synthetic scenarios estimating gravity and, gravitational gradient change based on the Okubo elastic half space model. We consider a typical fault with a strike angle to be $20^{\circ}$, fault length to be $380 \mathrm{~km}$, fault width to be $40 \mathrm{~km}$, dip angle to be $80^{\circ}$, depth of top edge of fault to be $5.67 \mathrm{~km}$, slip magnitude to be $5 \mathrm{~m}$ and rake angle to be $0^{\circ}$ (left lateral strike slip). To reveal the sensitivity of the model to a specific fault parameter, all other fault parameters are fixed to the chosen values, with only the looked-for parameter as a variable.

In order to evaluate the sensitivity of model to strike angle, the values $20^{\circ}, 30^{\circ}, 90^{\circ}, 150^{\circ}, 210^{\circ}$ and $360^{\circ}$ are set for the strike angle. According to Figure 3 , as the strike angle increases clockwise from $20^{\circ}$ to $360^{\circ}$, the spatial pattern of the $\Delta \mathrm{Vxz}$ rotates clockwise in the same manner.

To test the sensitivity of model to the fault length,

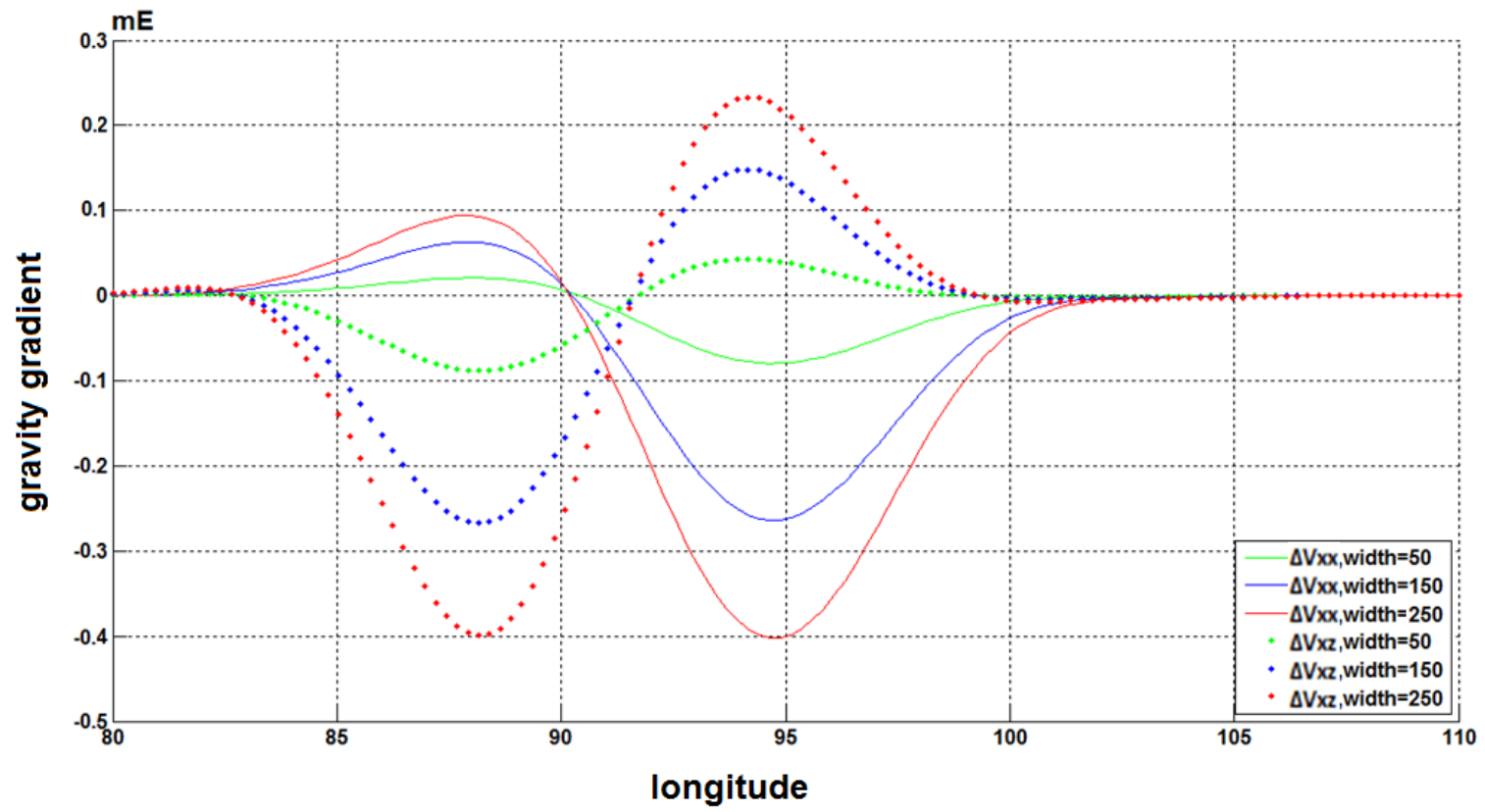

Figure 5. Sensitivity to with of a fault: pattern of gravity gradient changes for the profile along $3^{\circ} \mathrm{N}$ for widths of $50 \mathrm{~km}, 150 \mathrm{~km}$, or 250 $\mathrm{km}$, respectively. Center of the fault plane is fixed. Fault strike angle, length, dip angle, depth, slip, rake angle, are fixed at $20^{\circ}, 380 \mathrm{~km}, 80^{\circ}$, $5.67 \mathrm{~km}, 5 \mathrm{~m}, 0^{\circ}$, respectively. 


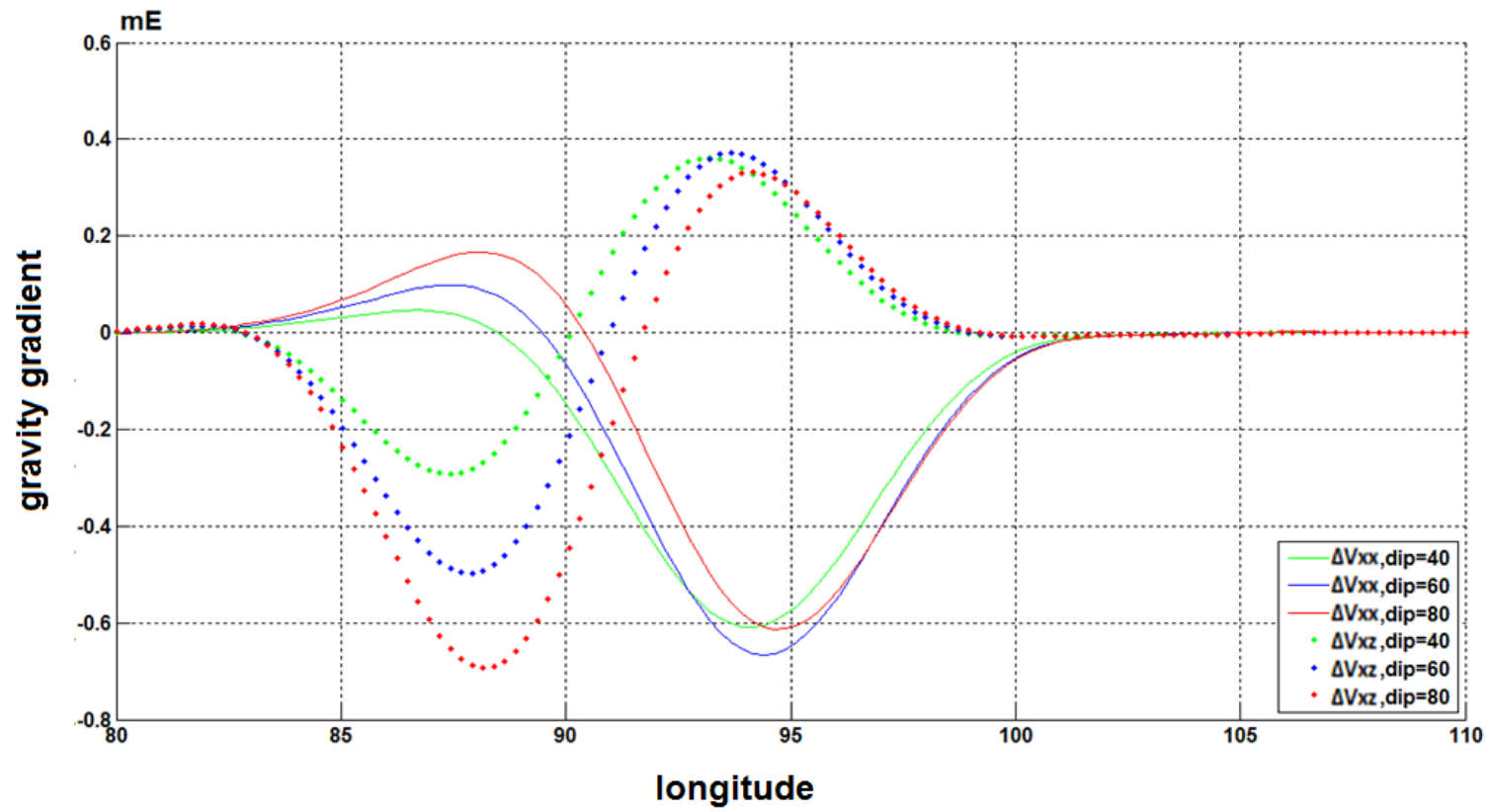

Figure 6. Sensitivity to dip angle of a fault: patterns of gravity gradient changes for the profile along $3^{\circ} \mathrm{N}$ for dip angle of $40^{\circ}, 60^{\circ}$, and $80^{\circ}$, respectively. Fault strike angle, length, width, depth, slip, rake angle, are fixed at $20^{\circ}, 380 \mathrm{~km}, 40 \mathrm{~km}, 5.67 \mathrm{~km}, 5 \mathrm{~m}, 0^{\circ}$, respectively. Center of the fault plane is fixed.

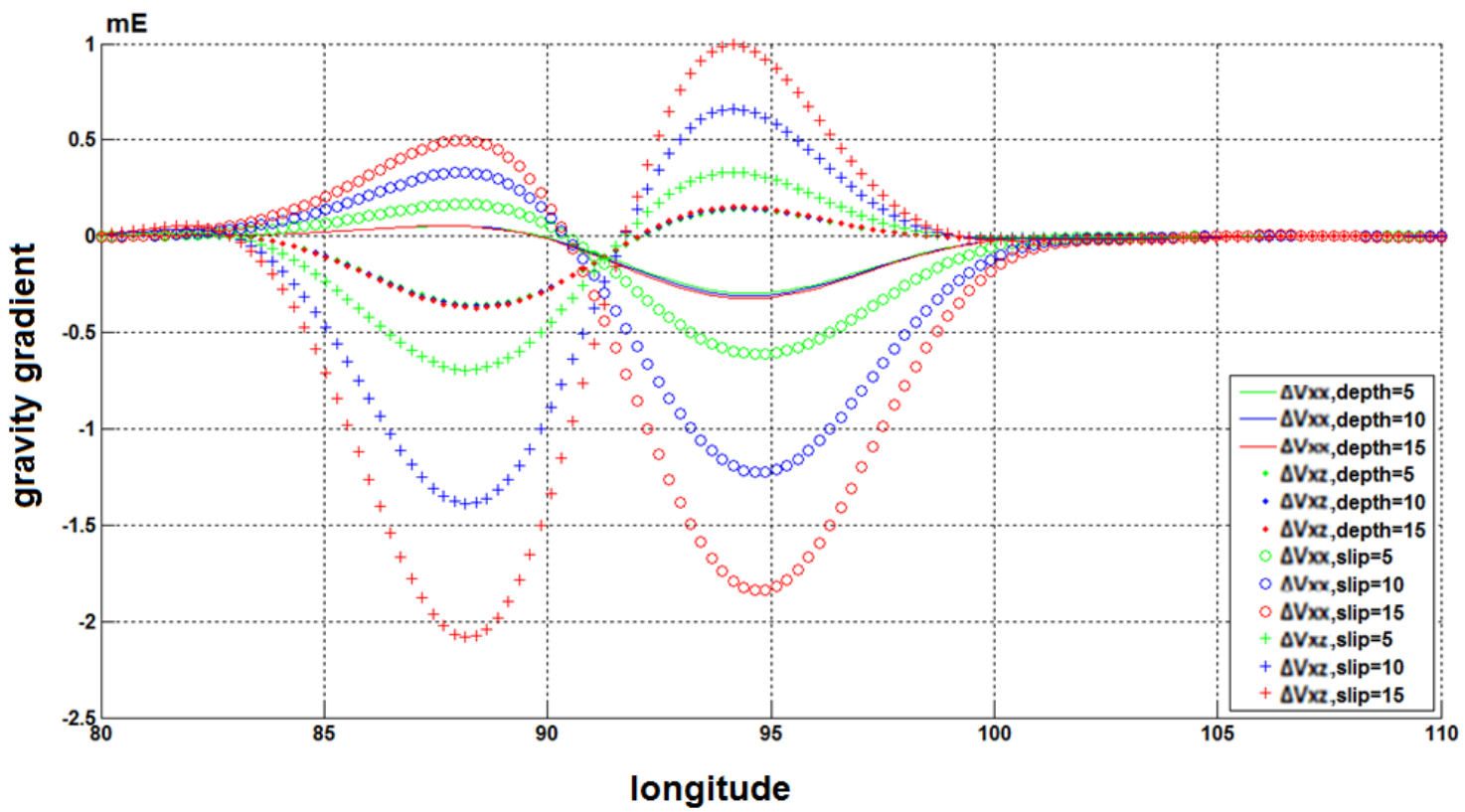

Figure 7. Sensitivity to depth and slip of a fault surface: Modeled gravity gradient changes for the profile along $3^{\circ} \mathrm{N}$ for depth of $5 \mathrm{~km}, 10 \mathrm{~km}$, and $15 \mathrm{~km}$, respectively and slip of $5 \mathrm{~m}, 10 \mathrm{~m}$ and $15 \mathrm{~m}$, respectively. Fault strike angle, length, width, dip, rake angle, are fixed at $20^{\circ}, 380 \mathrm{~km}$, $40 \mathrm{~km}, 80^{\circ}, 0^{\circ}$, respectively. Slip is $5 \mathrm{~m}$ in first case and depth is $5.67 \mathrm{~km}$ in second case. Center of the fault plane is fixed.

the values of $200 \mathrm{~km}, 400 \mathrm{~km}$, and $600 \mathrm{~km}$ are taken for the fault length, with all other parameters fixed and the variations of gravity gradient components $\Delta \mathrm{Vxx}$ and $\Delta V x z$ are considered. As shown in Figure 4, the spatial magnitude increases and signal pattern of $\Delta \mathrm{Vxz}$ is elongated along the strike direction. Thus, the broadness of the signal along the strike direction and the magnitude of the signal will provide constraint for the fault length.

For each width values of $50 \mathrm{~km}, 150 \mathrm{~km}$ and 250 $\mathrm{km}$, gravity gradient changes are computed for the profile along $3^{\circ} \mathrm{N}$ (Figure 5). As can be seen, $\Delta \mathrm{Vxx}$ and $\Delta V \mathrm{Xz}$ signal magnitudes increase while the position of peak values doesn't change. The pick negative value rise from -0.8 to -4 miliEotvos for $\Delta V x x$. Therefore, the sensitivity of gravity gradients to width is significant.

When dip angle takes on the values of $40^{\circ}, 60^{\circ}$, $80^{\circ}$, the magnitude of gravity gradient change increases since more mass around two sides of the fault plane is deformed. As shown in Figure 6, the signal shifts to the east for about 0.5 degree when the dip angle increases. 
To test the sensitivity of the model to a depth parameter, the depth of the top edge of the fault takes the values of $5 \mathrm{~km}, 10 \mathrm{~km}$ and $15 \mathrm{~km}$ with all other parameters hold fixed. When the fault depth increases, the surface gravity change may decrease, since the deformed medium gets further away from the ground surface. However, it can also cause the increase in the gravity change since an additional volume of internal medium being elastically deformed as well. Thus the overall effect may be increase or decrease depends on the values of other parameters.

Figure 7 shows that the overall magnitude of gravity gradient increases with very low sensitivity.

Finally, we consider changing of slip magnitude from $5 \mathrm{~m}$ to $15 \mathrm{~m}$. One can see in Figure 7 that it increases gravity gradient field very much and this parameter provides a good constraint on the fault plane.

The result of the sensitivity analysis revealed that the model is sensitive to most of the fault parameters such as slip, dip, strike, width, length and is less sensitive to the depth.

\section{Focal mechanism of Indian Ocean earthquake}

In this section, the GRACE gravity gradient components, $\Delta V x x$ and $\Delta V x z$, resulting from Indian Ocean earthquake are used to constrain the corresponding fault parameters using Okubo [1992] model. As was shown in the previous section, the selected components of gravity gradient, computed from Okubo model [1992], are not very sensitive to the fault depth, thus it is suggested to fix the depth of the fault to a known value and use the depth information from other sources. For the Indian earthquake, Wei [2012] suggested that the rupture started from $5.67 \mathrm{~km}$ depth along the mega thrust interface. Thus, we may fix the depth for the top edge of the fault as $5.67 \mathrm{~km}$. The rake angle is also fixed as $0^{\circ}$ in our inversion, i.e., we only invert for the left-lateral strike slip component and neglect thrust component. This simplification can be justified by Wei [2012] results, which showed that the thrust (dip-slip) seismic moment is one order of magnitude smaller than the strike-slip seismic moment.

In order to estimate the remaining fault parameters including, strike angle, dip angle, length, width and average slip, the genetic algorithm is used to solve the following nonlinear equation:

$$
R=l-F(\alpha, \delta, L, W, U)
$$

In which $\mathrm{R}$ (evaluate function) is a residual norm between observation (1), which is obtained from
GRACE data, and the function $\mathrm{F}$ which is obtained from Okubo model [1992]. $\mathrm{F}$ is either $\Delta \mathrm{Vxx}$ or $\Delta V \mathrm{Vxz}$, which is a function of $\alpha, \delta, L, W$ and $U$ which are strike angle, dip angle, length, width and average slip, respectively.

The key parts of the inversion, are the "evaluate" and "Okubo" functions. The "evaluate" function defines the meaning of fitting. In this instance, it is the sum of the absolute differences between the computed gravity gradient changes from Okubo model, and the measured gravity gradient changes from GRACE data. To minimize this fitting index is the goal of inversion algorithm. To do so, the model is run with many set of initial values for $\alpha, \delta, \mathrm{L}, \mathrm{W}$ and $\mathrm{U}$, and in each case, the computed gravity gradient change by Okubo model is compared with the gravity gradient change obtained from GRACE observation to compute the R criteria in Equation (2). The set of parameters, among all possible choices, that minimizes $\mathrm{R}$ is selected as an optimal solution.

It should be noted that the gravity or gravitational gradient change computed by the analytical mod$\mathrm{el}$, has different spatial resolution compared with the spatial resolution of GRACE observation. Thus, we need to make the model predictions consistent with GRACE results. In order to do that, we disassemble the model-predicted gravity change into spherical harmonic coefficients to a degree and order 60 commensurable with the respective GRACE data products, and then a $350 \mathrm{~km}$ isotropic Gaussian smoothing is used to cure the problem of spatial resolution.

To show the procedure for the model prediction, we calculate co-seismic gravity change for Indian Ocean earthquake, for selected set of fault parameters before and after mentioned corrections (e.g. seawater correction, free-air correction). The effects of isotropic Gaussian smoothing is also illustrated in Figure 8.

Moreover, we calculate the co-seismic gravity gradient change associated with Indian Ocean earthquake (Figure 9). Figure 9, first row, shows full gravity gradient tensor of Indian Ocean earthquake calculated by Okubo model [1992]. The GRACE-derived co-seismic gravity gradient tensor (Figure 9, second row) agrees well with the model prediction.

As you can see from Figure 9, $\Delta \mathrm{Vxx}$ and $\Delta \mathrm{Vxz}$ components dramatically suppress stripes errors and show a maximum positive gradient changes of $0.37 \pm$ 0.08 milliEotvos and $0.59 \pm 0.09$ milliEotvos respectively and the positive-negative-positive pattern of $\Delta \mathrm{Vxx}$ and $\Delta V x z$ distributed from north-west to south-east of the fault plane which agree well with the model predictions and other components are polluted with other 

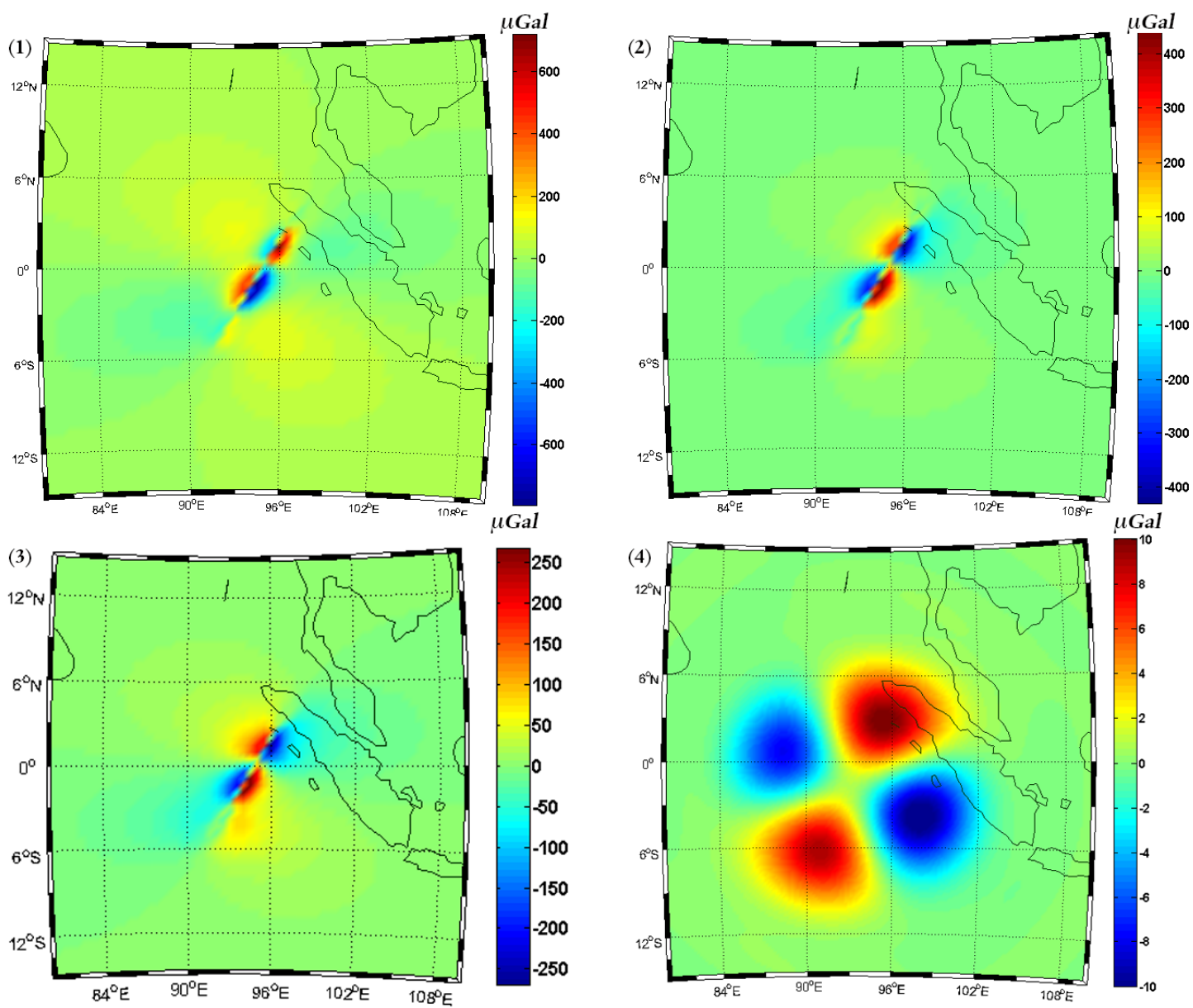

Figure 8. Dislocation model predictions of co-seismic gravity change due to the 2012 Indian Ocean earthquake using Okubo formulation. 1) Gravity change without free-air correction, 2) gravity change after free-air correction, 3) gravity change after free-air correction and seawater correction, and 4) corrected gravity change smoothed with $350 \mathrm{~km}$ Gaussian filter. (Units in $\mu \mathrm{Gal}$ ).

signals (e.g. striping and other noises). We know that GRACE stripe errors are distributed in north-south direction. Therefore by taking derivative with a respect to $\mathrm{x}$-axis (north direction) these variations dramatically suppress which can be seen in $\Delta \mathrm{Vxx}$ and $\Delta \mathrm{Vxz}$. But by taking derivative with a respect to y-axis, GRACE strip errors are enhanced which can be seen in $\Delta V x y, \Delta V y y$, $\Delta \mathrm{Vyz}$ components. Moreover the gravity gradient ob-

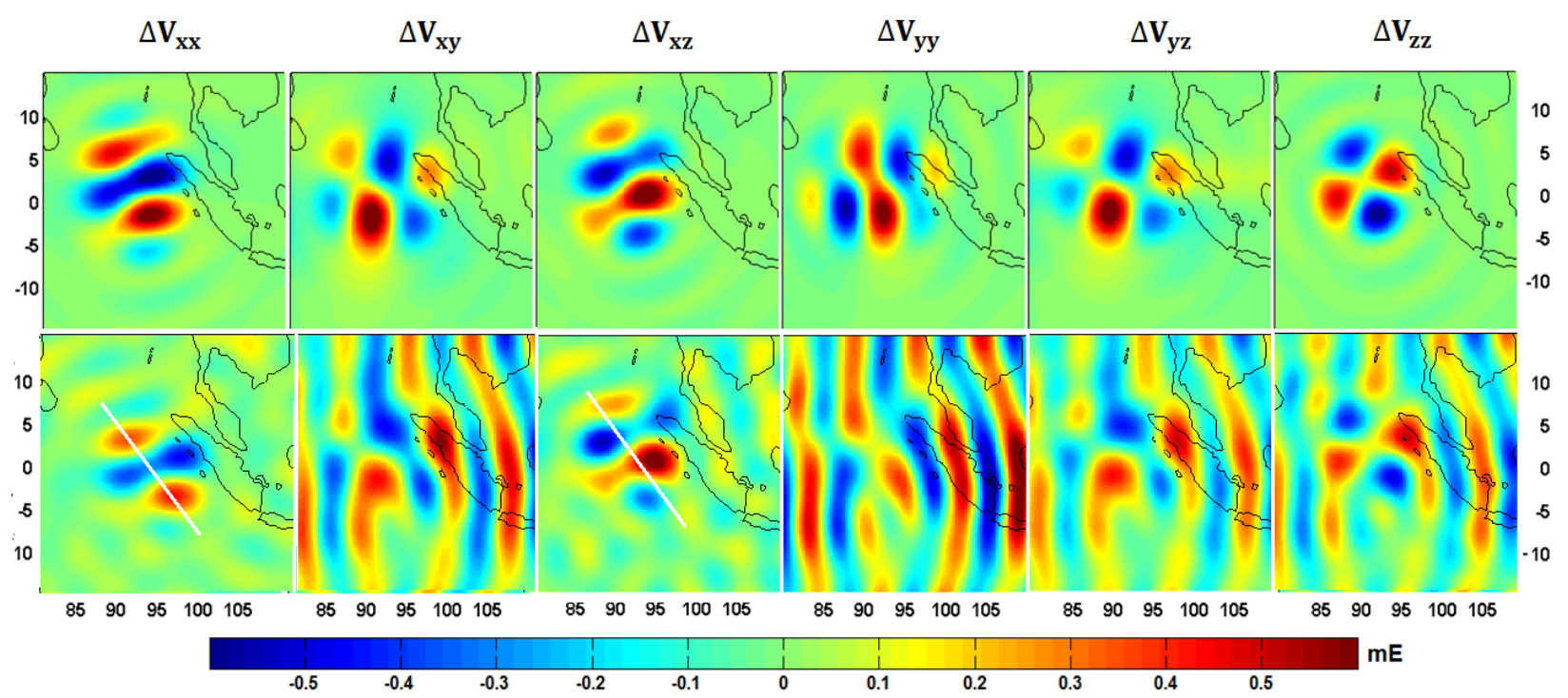

Figure 9. Modeled and observed gravitational gradient changes for the 2012 Indian Ocean earthquake, first row: Modeled co-seismic gravitational gradient changes (using Okubo formulation), second row: GRACE-derived gravitational gradient changes (Units in miliEotvos). White line is a chosen profile, which is used in Figure 11 and 12. 
tained in this way does need any de-striping and spatial smoothing procedure and thus the original signal does not disturb in this way. However, for gravity observation of GRACE, at least the Gaussian filtering should be applied in order to refine the co-seismic signal.

In order to show that the selected gravity gradient components have better consistency with both analytical model and GRACE observation, we quantify the goodness of fit criteria by computing the R2 statistics (i.e., variance reduction). Variance Reduction (VR) of the GRACE observations with a seismic model synthetics is defined as

$$
V R=1-\frac{\operatorname{var}(\text { data }- \text { model })}{\operatorname{var}(\text { data })}
$$

where $\operatorname{var}()$ is an operator calculating variance. VR is computed with six components of gravity gradient tensor. Figure(10) shows R2 statistics with different gravity gradient components. The GRACE-derived co-seismic gravity gradient tensor (Figure 9, second row) agrees well with model predictions yielding more than $50 \%$ of VR. Moreover, the two gravitational gradient components, $\Delta \mathrm{Vxz}$ and $\Delta \mathrm{Vxx}$ better fit the GRACE data yielding more than $60 \%$ of VR. According to Figure 10, among six components of gravity gradient tensor, we can arrange $\Delta \mathrm{Vxz}, \Delta \mathrm{Vxx}, \Delta \mathrm{Vxy}$, $\Delta \mathrm{Vzz}, \Delta \mathrm{Vyz}$ and $\Delta \mathrm{Vyy}$ in a decreasing order of VR. $\Delta$ Vyy has distinctly poorer agreement with the value of VR less than $45 \%$ Therefore, we use these two components to constrain the fault parameters.

The ultimate optimal estimate for fault length, width, dip, strike and slip are, $364 \mathrm{~km}, 58 \mathrm{~km}, 77^{\circ}, 23^{\circ}$ and $5.4 \mathrm{~m}$, respectively, which have been evaluated by the inversion of $\Delta \mathrm{Vxx}$ component. Figure 11 shows $\Delta \mathrm{Vxx}$ along the chosen profile across the fault (this profile has been shown by white line in Figure 9 for both $\Delta V x x$ and $\Delta V x z)$. The green curve related to GRACE results and the blue curve is related to Okubo model.

The ultimate optimal estimate for fault length, width, dip, strike and slip are, $387 \mathrm{~km}, 52 \mathrm{~km}, 81^{\circ}, 22^{\circ}$ and $5.9 \mathrm{~m}$, respectively which have been determined by the inversion of $\Delta V x z$ component. Figure 12, shows $\Delta \mathrm{Vxz}$ along the chosen profile across the fault (this profile has been shown by white line in Figure 9 for both $\Delta V x x$ and $\Delta V x z)$. The green curve related to GRACE results and the blue curve is related to Okubo model.

In order to define the lower and upper bounds of the error estimate for the components of GRACE observations in the inversion process, the parameter uncertainties are calculated by the errors in the GRACE observations. The difference between the lower and the upper bounds of the GRACE data estimates of fault-plane length, width, dip, strike and slip, calculating from $\Delta \mathrm{Vxz}$, are $11 \mathrm{~km}, 8 \mathrm{~km}$ and $1.1^{\circ}, 1.4^{\circ}$ and $1.3 \mathrm{~m}$ respectively when the algorithm converges to a fault plane.

In Table 1, we compare our results with five slip models (model I to $\mathrm{V}$ ) previously discussed at the introduction of this study. According to table 2, there are many discrepancies in slip models. This shows that there is a tradeoff among fault parameters. Furthermore, source parameter inversion using different

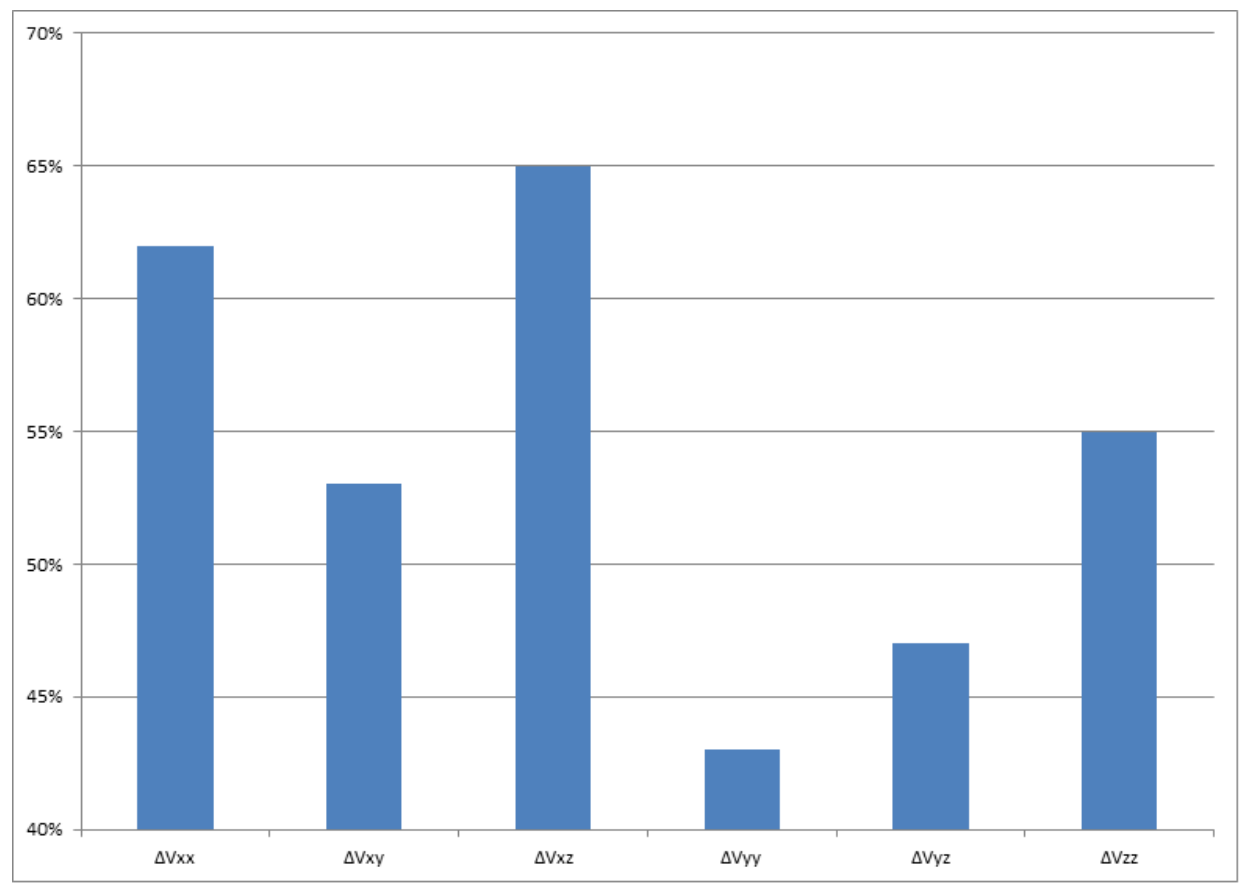

Figure 10. Variance Reduction (VR) of the GRACE observations and Okubo model for each component of gravity gradient tensor. 


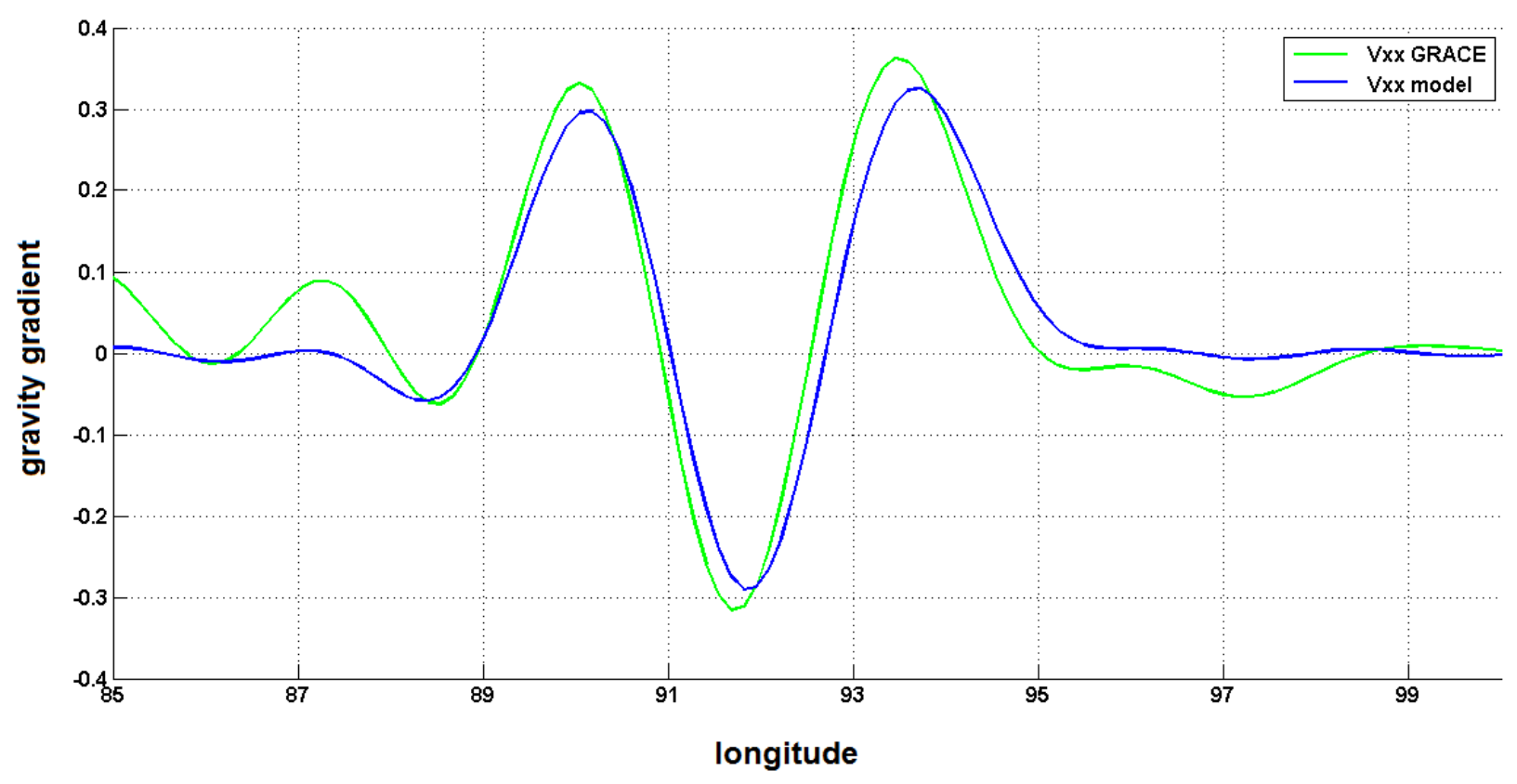

Figure 11. Comparison of $\Delta \mathrm{Vxx}$ obtained by Okubo model with $\Delta \mathrm{Vxx}$ computed from GRACE observation along the white profile in Figure 9 (Units in miliEotvos).

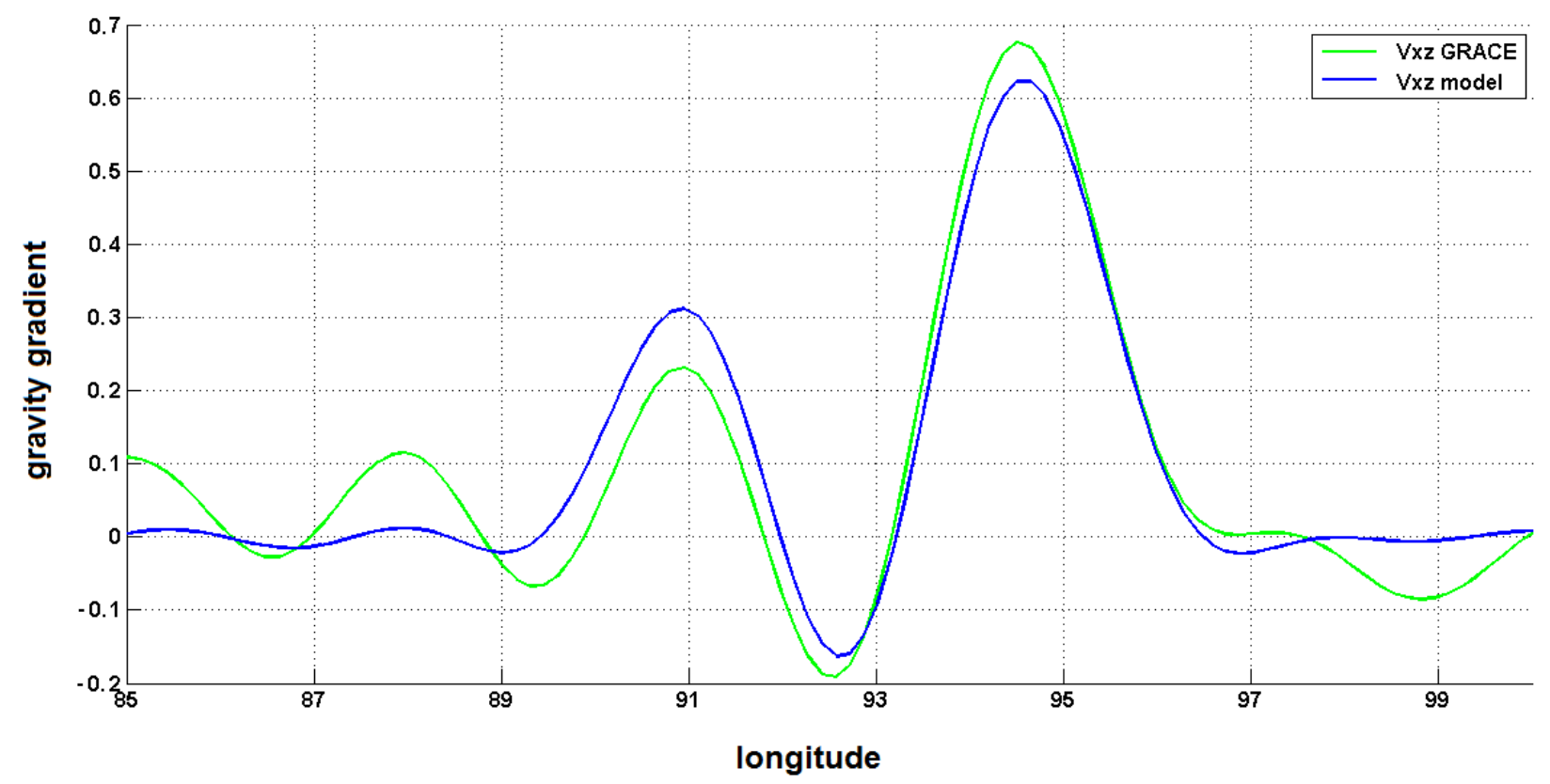

Figure 12. Comparison of $\Delta \mathrm{Vxz}$ obtained by Okubo model, with $\Delta \mathrm{Vxz}$ computed from GRACE observation along the white profile in Figure 9 (Units in miliEotvos).

source of data may result in a different fault geometry and fault parameters. The total seismic moment $\mathrm{M}=$ $\mu \mathrm{ULW}$ where $\mu$ is a mean rigidity (assuming mean rigidity of $33 \mathrm{GPa}$ quoted from Vigny et al. [2011]), is also shown in this table.

\section{Conclusion}

In this study, using the observations of Level 02, monthly gravity field solution of GRACE satellites, the changes in the gravity gradient tensor resulting from Indian Ocean earthquake have been derived. It is shown that the two components of the gravity gradient, namely, $\Delta \mathrm{Vxx}$ and $\Delta \mathrm{Vxz}$ are free from striping error of GRACE observations distributed in the north-south direction. By suppressing the effects due to seasonal variation of hydrological source and the influences of post seismic deformation, the co-seismic signal is recovered. Finally, the co-seismic gravity gra- 


\begin{tabular}{|c|c|c|c|c|c|c|}
\hline model & $\mathbf{L}(\mathbf{k m})$ & $\mathbf{W}(\mathbf{k m})$ & $\operatorname{Dip}\left(^{\circ}\right)$ & Strike $\left(^{\circ}\right)$ & $\operatorname{Slip}(\mathbf{m})$ & $\begin{array}{l}\text { Total seismic } \\
\text { moment }(\mathrm{Nm})\end{array}$ \\
\hline This study (Vxx) & 364 & 58 & 77 & 23 & 5.4 & $3.76 \times 10^{21}$ \\
\hline This study (Vxz) & 387 & 52 & 81 & 22 & 5.9 & $3.91 \times 10^{21}$ \\
\hline Model I & 384 & 60 & 64 & 20 & & $8.9 \times 10^{21}$ \\
\hline Model II & 380 & 40 & 80 & 20 & & $1.02 \times 10^{22}$ \\
\hline Model III & 375 & 40 & 79.95 & 198.87 & & $7.76 \times 10^{21}$ \\
\hline Model IV & 255 & 48 & 86.98 & 108.34 & & $7.76 \times 10^{21}$ \\
\hline Model V & & & & & & $1.26 \times 10^{22}$ \\
\hline
\end{tabular}

Table 1. Different slip models for Indian Ocean earthquake.

dient change are compared with the analytical model of Okubo [1992] to invert for fault parameters. Moreover, we demonstrate that GRACE data can provide a good constraint to fault length, width, strike, dip and slip of Indian Ocean earthquake, but it is not suitable to invert for fault depth. The ultimate optimal estimates for fault length, width, dip, strike and slip are, $387 \mathrm{~km}, 52 \mathrm{~km}, 81^{\circ}, 22^{\circ}$ and $5.9 \mathrm{~m}$, respectively which are computed by the inversion of $\Delta \mathrm{Vxz}$ component. On the other hand, the inversion of $\Delta V \mathrm{Vx}$ results in the values of , $364 \mathrm{~km}, 58 \mathrm{~km}, 77^{\circ}, 23^{\circ}$ and $5.4 \mathrm{~m}$, for fault length, width, dip, strike and slip respectively.

Acknowledgements. We would like to express our deepest appreciation to all those who provided us the possibility to complete this paper. we would like to acknowledge with much appreciation the crucial role of the scientists; Professor C.K. Shum, Professor W. B. Shen, Professor W. Sun, Doctor J. Li and Doctor C. Dai who gave us great tips and respond to our emails.

\section{References}

Broerse, D., L. Vermeersen, R. Riva, and W. van der Wal (2011), Ocean contribution to co-seismic crustal deformation and geoid anomalies: Applicationto the 2004 December 26 Sumatra-Andaman earthquake, Earth Planet. Sci. Lett., 305(3-4), 341-349, doi:10.1016/j.epsl.2011.03.011.

Cambiotti G, Bordoni A, Sabadini R, Colli L (2011) GRACE gravity data help constraining seismic models of the 2004 Sumatran earthquake. J Geophys Res 116:B10403. doi:10.1007/s11589-0120849-z.

Chen, J. L., C. R. Wilson, B. D. Tapley and S. Grand (2007). GRACE detects co-seismic and post-seismic deformation from the Sumatra-Andaman earthquake, Geophysical Research Letters, 34, L13302, doi: $10.1029 / 2007 \mathrm{gl} 030356$.

Dai, C., C.K. Shum, R. Wang, L. Wang, J. Guo, K. Shang and B. Tapley (2014). Improved constraints on seismic source parameters of the 2011 Tohoku earthquake from GRACE gravity and gravity gradient changes, Geophys.Res.Lett. 41, 1929-1936, doi:
10.1002/2013GL059178.

Dai, C., C. Shum, J. Guo, K. Shang, B. Tapley, R. Wang (2016), Improved source parameter constraints for five undersea earthquakes from north component of GRACE gravity and gravity gradient change measurements, Earth Planet. Sci. Lett., 443, 118-128.

de Linage, C., Rivera L, Hinderer J, Boy JP, Rogister Y, Lambotte S,Biancale R (2009) Separation of co-seismic and post-seismic gravity changes for the 2004 Sumatra-Andaman earthquake from 4.6 year of GRACE observations and modelling of the coseismic change by normal modes summation. Geophys J Int176:695-714. doi:10.1111/j.1365246X.2008.04025.x.

Duputel, Z., H. Kanamori, V. C. Tsai, L. Rivera, L. Meng, J-P. Ampuero and J. Stock (2012). The 2012 Sumatra great earthquake sequence, Earth and Planet, Sci. Lett., 351-352, 247-257, doi: 10.1016/j. epsl.2012.07.017.

Fatolazadeh, F., Voosoghi, B., Raoofian Naeeni, M., (2015). Computation of the changes ingravitational gradient components using GRACE observations and analytical model. Acta Geod Geophys. 51 (4), 643-658. http://dx.doi.org/10.1007/s40328-0150152-2.

Fatolazadeh, F., Raoofian Naeeni, M., Voosoghi, B., Rahimi, A., (2017). Estimation of fault parameters using GRACE observations and analytical model. Journal of Geodynamics. 108, 26-39, DOI: 10.1016/j.jog.2017.05.004.

Han, S.-C., R. Riva, J. Sauber and E. Okal, (2013). Source parameter inversion for recent great earthquakes from a decade-long observation of global gravity fields, J. Geophys. Res. Solid Earth, 118, 1240-1267, doi:10.1002/jgrb.50116.

Han, S.-C, J. Sauber, F. Pollitz (2015). Co-seismic compression/dilatation and viscoelastic uplift/ subsidence following the 2012 Indian Ocean earthquakes quantified from satellite gravity observations, Geophys. Res. Lett., 42 3764-3722, doi: 
$10.1002 / 2015$ GL063819

Hayes, G., (NEIC, Sumatra 2012). Preliminary Result of the Apr 11, $2012 \mathrm{Mw} 8.6$ Earthquake Off the West Coast of Northern Sumatra,http://earthquake.usgs.gov/ earthquakes / eqinthenews / 2012/ usc000905e/finite_fault.php,last accessed August 19, 2013.

Li, J., W. B. Shen (2011). Investigation of the co-seismic gravity field variations caused by the 2004 Sumatra-Andaman earthquake using monthly GRACE data, J. Earth Sci., 22:280-291, doi:10.1007/s12583011-0181-x.

Li, J., J. L. Chen, Z. Z. Zhang (2014). Seismologic applications of GRACE time-variable gravity measurements, Earthq. Sci., 27(2):229-245, doi:10.1007/ s11589-014-0072-1.

Okada Y (1985) Surface deformation due to shear and tensile faults in a half-space, Bull Seism Soc Am 75:1135-1154.

Okubo, S., (1991). Potential and gravity change raised by point dislocations, Geophys. J. Int., 105, 573586,doi: 10.1111/j.1365-246X.

Okubo, S., (1992). Gravity and potential change due to shear and tensile faults in a halfspace, J. Geophys. Res., 97(B5), 7137, doi: 10.1029/92JB00178.

Shao, G., X. Li and C. Ji (UCSB, Sumatra 2012). Preliminary Result of the Apr 11, $2012 \mathrm{Mw} 8.64$ Sumatra Earthquake,http: / /www.geol.ucsb.edu/faculty / ji/big_earthquakes/2012/04/10/sumatra.html.

Sneeuw, N., (1994). Global spherical harmonic analysis by least-squares and numerical quadrature methods in historical perspective, Geophys. J. Int, doi: 10.1111/j.1365-246X.1994.tb03995.x.

Stein, S., Geller, R. J., \& Liu, M. (2012). Why earthquake hazard maps often fail and what to do about it. Tectonophysics, 562-563, 1-25. doi: 10.1016/j. tecto.2012.06.047

Sun, W., and S. Okubo, (1993) Surface potential and gravity changes due to internal dislocations in a spherical earth-I. Theory for a point dislocation, Geophys. J. Int., 114, 569- 592.

Sun, W., and S. Okubo, (1998) Surface potential and gravity changes due to internal dislocations in a spherical earth-II. Application to a finite fault, Geophys. J. Int., 132, 79- 88.

Sun W, S., G. Okubo, G. Fu, A. Araya (2009). General formulations of global co-seismic deformations caused by an arbitrary dislocation in a spherically symmetric earth model: applicable to deformed earth surface and space-fixed point, Geophys. J. Int., 177:817-833, doi:10.1111/j.1365-246X.2009.04113.x.
Sun W., Fu G., Okubo S. (2010) Co-seismic Gravity Changes Computed for a Spherical Earth Model Applicable to GRACE Data. In: Mertikas S. (eds) Gravity, Geoid and Earth Observation. International Association of Geodesy Symposia, vol 135. Springer, Berlin, Heidelberg.

Tapley, B., Bettadpur, S., Ries, J., Thompson, P. \& Watkins, M., 2004. GRACE measurements of mass variability in the Earth system, Science, 305, 503-505.

Wang, L., C. K. Shum, F. J. Simons, A. Tassara, K. Erkan, C. Jekeli, A. Braun, C. Kao, H. Lee, D-N. Yuan (2012a). Co-seismic slip of the $2010 \mathrm{Mw} 8.8$ Great Maule, Chile, earthquake quantified by the inversion of GRACE observations, Earth and Planetary Science Letters, 335-336, 167-179, doi: 10.1016/j. eps1.2012.04.044.

Wang, L., C. K. Shum, F. J. Simons, B. Tapley and C. Dai (2012b). Co-seismic and post-seismic deformation of the 2011 Tohoku-Oki earthquake constrained by GRACE gravimetry, Geophysical Research Letters, 39, L07301, doi:10.1029/2012GL051104.

Wang, L., C. K. Shum, C. Jekeli (2012c). Gravitational gradient changes following the 2004 December 26 Sumatra-Andaman Earthquake inferred from GRACE, Geophysical Journal International, 191(3), 1109-1118, doi: 10.1111/j.1365-246X.2012.05674.x.

Wei S. (Caltech, Sumatra 2012). April/11/2012 (Mw 8.6), Sumatra. Source Models of Large Earthquakes. http://www.tectonics.caltech.edu/slip_ history/2012_Sumatra/index.html.

Yue, H.T., Lay, K.D., Koper (2012)En Echelon andOrthogonal Fault Ruptures of the 11 April 2012 Great Intraplate Earthquakes. Nature490245-249doi:10.1038/ nature11492.

\footnotetext{
*Corresponding author: Armin Rahimi

Faculty of Surveying and Geomatics Engineering, University of Tehran, Tehran, Iran;

email: armin_rahimi@ut.ac.ir.

2017 by Istituto Nazionale di Geofisica e Vulcanologia.

All rights reserved
} 